\title{
The Impact of Gas Flaring On Man and His Environment and the Way Out
}

\author{
A. KWAME SEKYI \\ Petroleum Engineering Department, University of Mines and Technology, Tarkwa Ghana, addosekyi@gmail.com
}

Abstract. The nature of flaring processes has created a severe impact on man and the environment. Massive environmental degradation as a result of flaring activities has led to fluctuations in climate as well as depletion of the vegetation cover through acid rain. Findings have been made on some harmful gases released into the atmosphere that have effects on the environment and also on man. In order to control these effects by ensuring a clean atmosphere and environment, a new flaring model (DanMat flaring model) has been suggested. The model uses smoldering mechanism to reduce the amount of heat released into the atmosphere during conventional flaring by 60\%. It also uses scavengers to oxidize harmful gas produced during flaring activities into less harmful ones. With this model one can flare gas without polluting the environment since it reduces the emissions of harmful gases during flaring.

\section{Introduction}

The Impact of Gas Flaring on Man and His Environment has become a problem over the years. Gas flaring is the disposal of unwanted associate natural gas released from an oil field through burning. It is widely used where there is no infrastructure to make use of the gas. However it is widely recognized as a waste of energy and environmentally dangerous in contributing carbon emissions to the atmosphere [1, 2]. The emission of carbon and some other harmful waste substances $\left(\mathrm{H}_{2} \mathrm{~S}, \mathrm{SO}_{2}\right.$, etc. $)$ as well as the release of tremendous heat as a result of gas flaring has a severe impact on man and his environment. However gas flaring cannot be eliminated totally; this means that it will continuously have a greater impact on man and his environment from generation to generation. This paper seeks to use theoretical approach to investigating into some environmental consequences and the effects of gas flaring on man and his environment and suggests some mechanisms to help bring under control the effects of gas flaring.

\section{History of Technologies Employed}

For the past decade or more many technological ways of improving on the use of produced gas rather than flaring are in existence, some measures were ensured to help control the production of the associated gas. Below are some reviewed technological ways. 


\subsection{Smart Automation Systems}

In an effort to reduce emissions of gas by venting, British Petroleum (BP) developed a "Smart Automation Well Venting System" technology that combines Remote Terminal Units (RTU) and Programmable Logic Controllers (PLC) with artificial intelligence software in the gas wells. The software monitors and analyzes data from wellhead instruments and lets the PLC optimize well performance by adjusting the gas lifting cycle. BP installed pilot systems starting in 2000 on about 2, 200 wells, and reduced venting by about $50 \%$ between 2000 and 2004 with about 114 billion cubic metres of associated gas savings in total.

\subsection{Natural Gas Hydrates (NGH)}

NGH is crystallized natural gas, which is a solid material in an ice state and chemically stable at -20 degrees Celsius. The stabilizing temperature is considerably higher than the LNG temperature of -162 degrees Celsius, which leads to lower capital, transportation, and storage costs. However, NGH is far less dense than Liquefied Natural Gas (LNG) and the quantity of gas transportable in hydrate form is correspondingly lower than LNG technology. NGH as a method to utilize associated gas is still in the research phase, but Mitsui and Mitsubishi, the British Gas group (BG), and Marathon Oil are leading the efforts to develop gas to-solids technology to produce and transport NGH [7]. Technologies that convert gas to-dimethyl ether, and ammonia Methane in natural gas and associated gas can also be converted to methanol. Methanol is further used to produce dimethyl ether (DME) and olefins such as ethylene and propylene in simple reactor systems, conventional operating conditions, and commercial catalysts. Methane in associated gas can also be converted to ammonia via the Haber process to produce nitrogen fertilizers. This method is quite common in Persian Gulf oil-producing states, especially in Saudi Arabia, Qatar, and the UAE, as well as Trinidad, another major methanol and ammonia producer [7].

John Zink Hamworthy's pursuit for reducing emissions and also control pollution with valuable pay back, engineered a comprehensive Flare Gas Recovery Solutions. John Zink Hamworthy's Combustion designs advanced flare gas recovery system to achieve the benefits of near-zero flaring. The combustion designs results near hundred percent reduction of normal flaring, limiting flare operation to emergency release and schedule maintenance [7].

\subsection{Gas Flow Meters}

The available methods to measure flared and vented gas flow rates associated with oil production include ultrasonic flow meters, optical flow meters, insertion turbines, averaging pitot tubes, and thermal mass meters. Some of these traditional technologies such as insertion turbines, pitot tubes, differential pressure flow meters, and thermal mass meters are limited by such factors as high flow velocities, large pipe diameters, changing gas composition, low pressure, dirt, wet gas, wax, condensate, and high concentrations of contaminants such as $\mathrm{CO}_{2}$ and $\mathrm{H}_{2} \mathrm{~S}$. Ultrasonic flow meters have been in use since 1987. They measure flow velocity by determining the time it takes for an ultrasonic 
pulse to travel between two fixed transducers located in the pipe. Ultrasonic meters are a costeffective solution for measurement of flare gas volumes. They are independent of pipe size and are not affected by extreme flow velocities and changing gas composition. They have no mechanical moving parts and their maintenance is minimized through self-diagnostics. Their measurement accuracies range from $2.5 \%$ to $5 \%$ of the actual values Orifice and venturi meters can be used instead of ultrasonic meters for stable gas flows, and they are applicable to wet and dry gas streams containing contaminants. However, they do not perform well for a broad range of flow rates, and need to be calibrated frequently for changing gas composition [3].

\subsection{Liquefied Natural Gas (LNG)}

LNG technology uses a straightforward refrigeration process. The gas is pre-treated for impurities such as sulphur, $\mathrm{CO}_{2}$, water, and other contaminants, transformed into liquid by being cooled to -162 degrees Celsius, and stored until it is shipped on board LNG tankers. New technologies are emerging to reduce the capital costs of the LNG process by eliminating this pre Microlex LPG Extraction Process. An example of such a process, called Micro-cell, was developed by Curtin University in Australia and is expected to reduce the capital costs of the conventional LNG process by $20 \%$ to $40 \%$. The resulting volume of the liquefied gas is about $1 / 600$ of the original volume in the gas phase [6]. After transport to a receiving terminal, the liquefied gas is

re-gasified for use in gas markets. A new LNG technology concept that has yet to be developed and proven commercially is called floating LNG (FLNG). This process is a combination of conventional LNG and floating deep water offshore production technologies. The combined FLNG vessels will contain liquefaction facilities onboard, and can be moved to small and remote oil fields easily, without having the need to build large, new facilities at each location. This concept is largely advocated by Shell [7] and the first commercial applications are likely to be in Australia at remote Browse Basin gas fields. The relatively low concentrations of gas associated with oil production may still fall below the commerciality threshold of FLNG, which requires inputs of about 10 million cubic metres per day. LNG products are generally used as fuels in power generation, heating, and industrial processes. The most important markets for LNG produced in West Africa are in Europe and the Americas [6].

According to the International Energy Agency, none of the current gas utilization technologies and methods is economical if the associated gas volumes are below 10 million cubic meters per day and the oil field is located more than $2,000 \mathrm{~km}$ from the closest market. In such situations, IAE recommends economic incentives and governmental regulations to prevent the flaring activities. In the case of relatively short distances to markets and low gas volumes, electricity generation or pipeline transport of the gas might become economical alternatives to flaring. If the gas volumes are higher than 10 million cubic meters per day and distances to markets are greater than $2000 \mathrm{~km}$, there are some other options to utilize the gas, including LNG or Gas To Liquid (GTL) plants, and transporting the liquids produced via tankers to the market locations so that it can then be reused as valuable feedstock. 
All these literature make a head on for minimizing gas flaring. Due to technology, incentives, infrastructure, costs etc. involved make the facilities needed to be installed in other to achieve these aims quite challenging. Most companies continue to flare and the consequence still remains in the environment. This project is carried out to add onto the remedies in the system and also put some immediate measures to control the menace flaring is imposing on the environment where operating companies on one way or the other failed to implement the reviewed technological plans that are at their disposal. Also this project looks to control the current impact of flaring as the world awaits the implementation of various technologies as planned to utilize associated gas to attain better economic and social growth.

\subsection{Why the Pollution Effects}

The emissions from flaring which are very hazardous to the environment depend on the chemical composition of the natural gas. The effects posed on the environment by the emission include but not limited to global warming as a result of the release of greenhouse gases, acidification of rain or acid rain, close heating of surrounding vegetation, surrounding air etc. As emissions occur, it gradually depletes or destroys the natural protection or shield (ozone layer) in the case of global warming. This destroyed layer cannot be replaced and hence its advent effects. During flaring the common mixture of gases emitted include $\mathrm{CO}, \mathrm{H}_{2} \mathrm{~S}, \mathrm{NO}_{\mathrm{X}}$, etc. these gases are emitted into the atmosphere reacting with rain water. This rain is diagnosed of being acidic that reduces the fertility of the soil, as this continues for a longer period of time, farm land around the flaring zone are greatly affected and in turn affect the vegetation cover. The pollution effects are seen to be the continuous practices of flaring that permanently destroys the natural state of the environment. It is just as in the case of none renewable resources, when it is depleted totally, there is no replacement and goes forever. Since methane is the major component of associated gas or natural gas, direct venting i.e. releasing of gas direct to the environment releases a significant amount of methane into the atmosphere. Flaring of associated gas, on the other hand, usually emits carbon monoxide (CO). The National Oceanic and Atmospheric Administration (NOAA) estimates that between years 1994 to 2008, the total amount of global gas flared was $2.4 \times 10^{12} \mathrm{~m}^{3}$, which corresponds to $70 \%$ of total U.S. greenhouse emissions in 2007 [4].

\section{Some Environmental Impact of Gas Flaring}

Emissions as a result of flaring contribute to a severe environmental impact due to the chemicals in the emissions; one of the effects is the cause of acid rain. Acid rain is any form of precipitation with high levels of nitric and sulphuric acids. It can also occur in the form of snow, fog, and tiny bits of dry material that settle on Earth. Nevertheless rotting vegetation and erupting volcanoes also release some chemicals that can cause acid rain, but most acid rainfall is attributed to human activities. The biggest culprit is the burning of fossil fuels typically flaring and also by coal-burning power plants, factories, and automobiles.

During flaring, Sulphur dioxide $\left(\mathrm{SO}_{2}\right)$ and nitrogen oxides $\left(\mathrm{NO}_{\mathrm{x}}\right)$ are released into the atmosphere. These chemical gases react with water, oxygen, and other substances to form mild solutions of 
sulphuric and nitric acid. These acidic solutions may be spread across the atmosphere and over hundreds of miles by winds. When acid rain reaches Earth, it flows across the surface in runoff water, thereby entering water bodies, and sinks into the soil. This rain (Acid rain) has many ecological effects, but none is considered greater than its impact on streams, wetlands, lakes, and other aquatic environments. Acid rain acidifies waters and causes them to absorb the aluminium that makes its way from soil into water bodies such as lakes and streams. This effect makes water bodies toxic to aquatic life, organisms such as crayfish, clams, fish, and other aquatic animals are greatly affected. It is noted that some species can tolerate acidic waters better than others. However, in an interconnected ecosystem, some species eventually impacts many more of the absorbed acids to other organisms throughout the food chain including non-aquatic species such as birds $[1,2]$.

Forests with much more exposure to acid rain can be destroyed, especially those at higher altitudes. This rain leaches off essential nutrients in the soil and releases aluminium into the soil, which makes it difficult for trees to absorb water. Leaves and shrubs of trees and plants are also harmed by the acids. The effects of acid rain, combined with other environmental impacts, leave trees and plants less able to withstand cold temperatures, insects, and disease. The pollutants may also inhibit trees' ability to reproduce.

Some soils are better and able to neutralize acids than others, this is usually found in areas where the soil's ability to withstand rapid pH fluctuation is low. The severe impact of acid rain are much greater, the only way to fight acid rain is by controlling the release of the pollutants that causes it. This means burning fewer fossil fuels (Flaring). Many governments are trying to find solutions to control emissions, these include the cleaning up of industry smokestacks and promoting an alternative fuel sources. The issue of acid rain cannot be dealt with today for an immediate responds, it would take decades for this problem to be solved [1,2]. Figure 1. shows the effect of acid rain on the growth of plant within the environment.

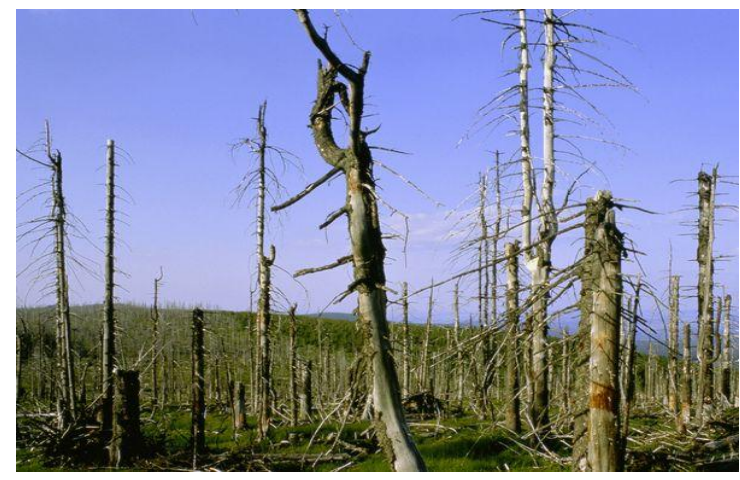

Figure 1. Effect of Acid Rain Felt Through the Food Chain

(Source: $[1,2]$ ) 


\section{Impact of Gas flaring on Man}

The investigations made are based on some selected wastes (gases) common to most production fields during flaring; these are $\mathrm{CO}, \mathrm{H}_{2} \mathrm{~S}$, and $\mathrm{NO}_{\mathrm{x}}$ gases. The detailed investigations are elaborated below.

\subsection{Carbon monoxide}

This is one of the harmful gases released during flaring; it is normally referred to as smoke. This gas causes reproduction problems to man which is normally identified as Reproductive toxicity of Carbon monoxide. Carbon monoxide is therefore a suspected and primary cause of reproductive toxicity. The exposure to it has the potential to negatively affect the human reproductive system. However, the gas has a wide range of applications in the food, chemical and oil industries. The severity and nature of the adverse effect is variable and can be influenced by factors such as sex, level of exposure and individual sensitivity to the chemical.

There is evidence which indicate that some women exposed to carbon monoxide may suffer adverse effects as a result. Carbon monoxide effects on the female reproductive systems can include such things as:

- Menstrual Problems, which include; Dysmenorrhoea, a medical term which means painful period, Menorrhagia which also means heavy periods.

- Altered Sexual Behaviour; in this effect the hormones for sex drives are lowered.

- Infertility; this is the inability of an individual to be reproductive.

- Altered Puberty Onset; the normal puberty onset for female (girls) is between the ages of 9 and 14, but the effect of the $\mathrm{CO}$ gas lowers the age range thereby causing girls to reach puberty prematurely.

- Altered Length of Pregnancy; the normal length of pregnancy in human (women) is 9 months, but the effect of $\mathrm{CO}$ on a pregnant woman causes her to deliver prematurely from 6 to 8 months.

- Lactation Problems; this is where the nursing mother lacks breast milk to nurse her baby due to the exposure of the gas.

- Altered Menopause Onset and pregnancy outcome; Menopause is the stage in which there is a declination in the production of hormones responsible for sex drives in women. The normal age is between 45 and 50 . The exposure of $\mathrm{CO}$ causes women to approach their menopause earlier before the actual age.

- Spontaneous abortion (miscarriage) and low birth weight are also possible adverse effects. The birth weight of a life born infant of less than 2, 500 grams can be described as Low Birth Rate. Regardless of the gestation age. These adverse effects are generally only likely to occur in cases involving chronic exposure to carbon monoxide.

Effects on the male reproductive system can include such things as altered sexual behavior, altered fertility and problems with sperm shape or count. These adverse effects are also likely to occur in cases where chronic exposure is observed though low concentrations of carbon monoxide (CO) also have adverse effects which include; fatigue in healthy people and chest pain in people with heart diseases. 
At higher concentrations, exposure can also cause impaired vision and coordination, headaches, dizziness, confusion and nausea just to mention a few. Acute effects are as a result of the formulation of carboxyhemoglobin in the blood, which inhibits oxygen intake.

Exposure to $\mathrm{CO}$ at moderate concentrations may result in angina attacks, impaired vision, and reduced brain function. CO exposure can be fatal at higher concentrations.

\subsection{Hydrogen Sulphide $\left(\mathrm{H}_{2} \mathrm{~S}\right)$}

Hydrogen Sulphide is a poisonous gas that has an adverse effect on humans as well as the environment. Exposure to low concentration of this gas causes irritation of the eyes, nose, or throat. In some cases it may also cause difficulty in breathing for someone suffering from asthma. Brief exposure to high concentration of hydrogen sulphide often (greater than $500 \mathrm{ppm}$ ) can cause a loss of consciousness and possibly, death. In most cases, the person appears to regain consciousness without any other effects. However in many individuals, there may be permanent or long term effects such as headaches, poor attention span, poor memory, and poor motor function.

\subsection{Nitrogen Oxides $\left(\mathrm{NO}_{\mathrm{x}}\right)$}

Nitrogen Oxides ( $\mathrm{NO}$ and $\mathrm{NO}_{2}$ ) are a mixture or family of gases that can cause a number of serious health effects. Nitrogen dioxide $\left(\mathrm{NO}_{2}\right)$ is unhealthy to breathe due to its complex health effects, especially for the under aged (children), the elderly, asthmatics and people suffering from chronic obstructive pulmonary diseases. However, $\mathrm{NO}_{\mathrm{x}}$ is also a key component to the formation of Ozone and Photochemical oxidants. Breathing low levels of ozone, for instance, can trigger asthma attacks and other problems for people with pre-existing respiratory problems. $\mathrm{NO}_{\mathrm{x}}$ also reacts with ammonia, and other compounds to form nitric acid and related particles. These tiny particles cause effects on breathing and the respiratory system, damage to lung tissues, and even premature death.

\section{Alternative Flaring Mechanism}

The alternative flaring mechanism suggested takes place in a model (DanMat Flaring model). This model uses polyurethane foam or cellulose, scavengers and calcium carbonate. The polyurethane foam eliminates the flaring flame as it uses smoldering mechanism. This is achieved by burning the gas with the polyurethane foam. The foam has distinct permeability which allows the flow of fuel (gas) through it. The gas to be flared is liquefied (LNG) so that it can be absorbed into the foam through its permeable pores and within an Enclosed Insulated Chamber the polyurethane foam together with the absorbed LNG is burnt.

The enclosed insulated chamber (combustion chamber) is designed to control the exposure of the burning process to excess oxygen. Since the presence of excess oxygen will cause the smouldering mechanism to burst into flame due to the absorbed liquefied gas, thus the absorbed gas makes the foam more combustible. In this case, the burning process is kept under smouldering mechanism. 
Although smouldering also produces heat of about $600{ }^{\circ} \mathrm{C}$ compared to about $1500{ }^{\circ} \mathrm{C}$, the temperature of the flame produced during conventional flaring. Smouldering thus reduces the heat temperature by $60 \%$. The Polyurethane foam is also a good insulator, so the combustion chamber is insulated using some of the foam. This totally prevented the remaining $40 \%$ of heat to be released into the environment.

Smouldering is often accompanied by smoke (Carbon monoxide CO); this smoke together with the mixture of gases released in an enclosed cylinder which is channeled through a pipe to another chamber called reaction chamber.

This chamber is designed purposely for the reaction of the released smoke or mixture of waste gases and a Scavenger $\left(\mathrm{H}_{2} \mathrm{~S}, \mathrm{CO}\right.$, and $\mathrm{NO}_{\mathrm{x}}$ scavenger). The scavenger considered is the Hydroxyl ion in its neutral state $\left(\mathrm{OH}^{\bullet}\right)$. The scavengers feed on these gases in the form of chemical reaction by deactivating $\mathrm{H}_{2} \mathrm{~S}, \mathrm{CO}$, and $\mathrm{NO}_{\mathrm{X}}$ which are very harmful.

The end products which are nothing but aqueous solutions, water, and carbon dioxide gas are formed. The $\mathrm{CO}_{2}$ gas produced is captured and stored for use. But if it is of no use then it is allowed to escape through the opening of the other end (stack) of the reaction chamber into the atmosphere.

The Flaring Model could be used to flare gas should the need arise without polluting the environment; it creates a serene environment in the working place and surrounding environment.

\section{Conclusion}

The investigations made on the release of some harmful wastes $\left(\mathrm{CO}, \mathrm{NO}_{\mathrm{x}}, \mathrm{H}_{2} \mathrm{~S}\right)$ show clearly that gas flaring has a severe impact on man and his environment. Therefore, if the appropriate measures are put in place as to how to manage or flare produced gas, the impact could be minimized.

The flare system (DanMat flaring system) suggested in this paper could help minimize the effects of gas flaring if adopted into the system. The model could minimize the tremendous heat released during conventional flaring from the temperature of $1,500{ }^{\circ} \mathrm{C}$ to $600{ }^{\circ} \mathrm{C}$ then to $0{ }^{\circ} \mathrm{C}$. In percentage-wise, it reduces the heat by $100 \%$ which is quite encouraging. It also digests the waste gases which are more harmful to man and the environment into a less harmful gas. This mechanism of gas flaring could be in place whiles planning of how to effectively utilize the produced gas so that the environment including man would not be affected that much.

\section{References}

[1] Anon. (2013), "Global Gas Flaring Estimates”, www.ngdc.noaa.gov. Accessed: January 30, 2013.

[2] Anon. (2013), "Effects of Acid Rain through Food Chain", www.environmet.nationalgeographic.com. Accessed: March 15, 2013. 
[3] Birnur, B. G., Robert, H. and Donald, H. (2010), Gas Flaring and Venting: Extent, Impact and Remedies James, Baker III Institute Publishers, USA, Vol. 1 pp. 25 - 37.

[4] Elvidge, C. D., Ziskin, D., Baugh, K. E., Tuttle, B. T., Gosh, T., Pack, E. H., Erwin, and Zhizhin, M. (2009), "A Fifteen Year Record of Global Natural Gas Flaring Derived From a Satellite data", Energies, Vol. 2 pp. 595 - 622.

[5] Farina, M. F. (2010), "Flare Gas Reduction”, GE Energy Global Strategy and Planning, GEA 18592, Setp, pp. 7 - 8.

[6] Lichun, D. W., Shiyu, T. and Hongjing, Z. (2008), “Gas to Liquids (GTL) or Liquid Natural Gas (LNG): Which is the Best way to monetise 'Stranded' Natural Gas?" Petroleum Science, Vol. 5 , pp. $1-3$.

[7] Marcano, J, and Cheung, R., (2007), “Monetising Stranded Natural Gas”, Oil and Gas Financial Journal, Vol. 1No. 1, pp. 3 - 7. 